\title{
Pathogenicity of Steinernema carpocapsae and S. glaseri (Nematoda: Steinernematidae) to Ixodes scapularis (Acari: Ixodidae)
}

\author{
ELYES ZHIOUA, ${ }^{1}$ ROGER A. LEBRUN, ${ }^{1}$ HOWARD S. GINSBERG, ${ }^{1,2}$ \\ AND ANDRE AESCHLIMANN ${ }^{3}$
}

Center for Vector-Borne Disease, Department of Plant Sciences, Woodward Hall, University of Rhode Island, Kingston, RI 02881

\begin{abstract}
J. Med. Entomol. 32(6): 900-905 (1995)
ABSTRACT The entomopathogenic nematodes Steinernema carpocapsae (Weiser) and S. glaseri (Steiner) are pathogenic to engorged adult, blacklegged ticks, Ixodes scapularis (Say), but not to unfed females, engorged nymphs, or engorged larvae. Nematodes apparently enter the tick through the genital pore, thus precluding infection of immature ticks. The timing of tick mortality, and overall mortality after $17 \mathrm{~d}$, did not differ between infections by $S$. carpocapsae and $S$. glaseri. These nematodes typically do not complete their life cycles or produce infective juveniles in I. scapularis. However, both species successfully produced infective juveniles when the tick body was slit before nematode infection. Mortality of engorged $I$. scapularis females infected by $S$. carpocapsae was greater than uninfected controls, but did not vary significantly with nematode concentration (50-3,000 infective juveniles per 5-cm-diameter petri dish). The $\mathrm{LC}_{50}$ was 347.8 infective juveniles per petri dish (5 ticks per dish). Hatched egg masses of infected ticks weighed less than those of uninfected controls. Mortality of infected ticks was greatest between 20 and $30^{\circ} \mathrm{C}$, and was lower at $15^{\circ} \mathrm{C}$.
\end{abstract}

KEY WORDS Ixodes scapularis, Steinernema carpocapsae, Steinernema glaseri, pathogenicity

SEVERAL METHODS ARE currently used to manage populations of Ixodes scapularis Say (=I. dammini Spielman, Clifford, Piesman \& Corwin [Oliver et al. 1993]), the principal vector of Lyme disease in North America (Piesman and Gray 1994). Acaricidal treatment, host manipulation, and habitat modification have shown variable success (Wilson and Deblinger 1993). These techniques also vary in their potential for negative environmental effects (Ginsberg 1994) and for the development of resistance by ticks (Solomon 1983). Potential biological control agents have been described, including the chalcid wasp, Hunterellus hookeri (Howard), and general predators such as grounddwelling birds, but their efficacy has not been demonstrated (Mather et al. 1987, Duffy 1991).

In conducting the research described in this report, the investigators adhered to the "Guide for the Care and Use of Laboratory Animals," as promulgated by the Committee on Care and Use of Laboratory Animals of the Institute of Laboratory Animal Resources, National Research Council. The facilities are fully accredited by the American Association of Laboratory Animal Care.

1 Center for Vector-Borne Disease, Department of Plant Sciences, Woodward Hall, University of Rhode Island, Kingston, RI 02881.

${ }^{2}$ National Biological Service, Department of Plant Sciences, Woodward Hall, University of Rhode Island, Kingston, RI 02881.

${ }^{3}$ Institute of Zoology, University of Neuchâtel, Chantemerle 22, CH-2000, Neuchâtel, Switzerland.
Steinernematid and heterorhabditid nematodes act as biocontrol agents against several soil-inhabiting insect species (Poinar 1979, Kaya 1990). The infective juvenile, which is the only free-living stage, persists in the upper soil layer where it seeks hosts by chemotactic orientation (Gaugler 1980, Kaya 1985). Persistence of infective juveniles depends on moisture, temperature, and nature of the soil and can be affected by the presence of parasites and predators (Kaya 1990). Once the infective juvenile enters the host, it releases symbiotic bacteria of the genus Xenorhabdus, which kills the host by septicemia (Akhurst 1982, Poinar 1986). Apparently, both nematodes and bacteria are required for substantial mortality of arthropod hosts (Dunphy and Thurston 1990). Each species of entomopathogenic nematodes has a characteristic Xenorhabdus species (Akhurst 1980). Steinernema carpocapsae (Weiser) and S. glaseri (Steiner) are associated, respectively, with $X$. nematophilus (Poinar and Thomas) and X. poinarii (Akhurst) (Akhurst and Boemare 1990).

These nematodes are pathogenic to a broad range of arthropod hosts including Japanese beetles, Popillia japonica (Newman) (Coleopetra: Scarabaeidae), black vine weevils, Otiorhyncus sulcatus (F.) (Coleopetra: Curculionidae), termites, 
Reticulitermes spp. (Isoptera: Rhinotermitidae), Mediterranean fruit fly larvae, Ceratitis capitata (Wiedemann) (Diptera: Tephritidae) (Klein 1990), cat flea larvae, Ctenocephalides felis (Bouché) (Sihponeptera: Pulicidae) (Silverman et al. 1982), and spiders, Pholcus phalangiodes (Fuesslin) (Arachnida) (Poinar 1989).

Unfortunately, there have been few studies on the susceptibility of ticks to entomopathogenic nematodes. Steinernema carpocapsae (strain All) and Heterorhabditis bacteriophora (Poinar) (strain HP88) are pathogenic against Boophilus annulatus (Say) females (Samish and Glazer 1992, Mauléon et al. 1993), but Amblyomma variegatum (F.) and B. microplus (Canestrini) are resistant to these nematodes (Barré et al. 1991, Mauléon et al. 1993). S. glaseri and S. carpocapsae inhabit the upper layer and the surface of the soil, which is also the habitat of engorged $I$. scapularis after drop-off from hosts. In this article, we examine the pathogenicity of $S$. carpocapsae and S. glaseri to engorged I. scapularis.

\section{Materials and Methods}

Steinernema carpocapsae (strain All) and S. glaseri (strain 326) were used in this study. Nematodes were reared on larval wax moths, Galleria mellonella (L.) (Lepidoptera: Pyralidae) (Poinar 1979, Woodring and Kaya 1988). Freshly collected infective juvenile nematodes from dead wax moth larvae were used for tick infestation.

Ticks were reared and maintained in the laboratory. Larvae, nymphs, and females were fed, on white footed mice, Syrian hamsters, and New Zealand white rabbits, respectively. All hosts were maintained, handled, and used in this research according to protocols approved by the Institutional Animal Care and Use Committee (protocol A9394008 ) at the University of Rhode Island. All 3 stages of I. scapularis were challenged with $S$. carpocapsae and S. glaseri. Pathogenicity of these nematodes was tested against engorged larvae, engorged nymphs, engorged females that had dropped off during the previous $24 \mathrm{~h}$ and unfed females.

Steinernema carpocapsae and $S$. glazeri survive best at low moistures (Kaya 1990). A high relative humidity is required for best survival of $I$. scapularis (Daniels et al. 1989). The bioassay was performed under conditions designed to provide an adequate environment for both nematodes and ticks. Infective juveniles of each nematode species were suspended in water. Five engorged $I$. scapularis females were placed in 5-cm-diameter petri dishes on filter paper (Whatman No. 1) and challenged with a concentration of 500 infective juveniles of $S$. carpocapsae or $S$. glaseri $(0.5 \mathrm{ml}$ of nematode suspension). Water only was applied to the control petri dishes. Each treatment was replicated 3 times. Dishes were incubated in a humid chamber $(90 \% \mathrm{RH})$ at $23.5^{\circ} \mathrm{C}$ in the dark and tick mortality was recorded daily. The same test was repeated using 5 unfed females, 10 engorged larvae, and 10 engorged nymphs.

Development of the nematodes in ticks was studied by dissecting ticks under a stereo microscope $21 \mathrm{~d}$ after death. The tick cadavers were surface-sterilized and bled, and drops of hemolymph were streaked on Tergitol (T7) agar plates containing triphenyltetrazolium chloride (TTC) (Akhurst 1980). Xenorhabdus sp. diagnosis was based on the shape and color characteristics of the colonies.

To test the relationship between nematode concentration and tick mortality, engorged $I$. scapularis females were challeged with several nematode concentrations: $50,500,1,500$, and 3,000 infective juvenile $S$. carpocapsae. The infective dose rate was evaluated by determining the $\mathrm{LC}_{50}$.

To observe the effect of nematodes on the fecundity of I. scapularis females, ticks that survived nematode infestation and uninfected control ticks were weighed and placed in separate vials. Fortythree days after repletion, eggs started to hatch. Two weeks after hatching, each vial with a hatched egg mass was weighed and the weight of an empty vial was subtracted.

To determine the effect of temperature on nematode pathogenicity, engorged $I$. scapularis females were incubated with 3,000 infective juvenile $S$. carpocapsae at $15,20,23.5,26$, and $30^{\circ} \mathrm{C}$.

Statistical Analysis. The $\mathrm{LC}_{50}$ was determined using the Reed-Muench method (Woolf 1968). Mortality was compared using chi-square tests and $G$ tests (Sokal and Rohlf 1981). Cumulative mortality through time was compared using Kolmogorov-Smirnov tests. The analysis of variance (ANOVA) for the fecundity experiment was performed with SYSTAT (SYSTAT 1992) and power was determined by the technique of Cohen (1988).

\section{Results}

Steinernema glaseri and S. carpocapsae were pathogenic only against engorged females (unengorged females were not affected by $S$. carpocapsae). Furthermore, all engorged larvae and nymphs molted after exposure to entomopathogenic nematodes. Symptoms of nematode infection in $I$. scapularis before death included numerous red spots on the body and stiffening of legs. Dead ticks were completly red (uninfected ticks were grey). No complicating infections such as fungal growth were observed. We observed nematodes entering through the genital pore, but not through the mouthparts, the anus or the spiracles (Fig. 1).

Tick mortality resulting from infection by $S$. glaseri and $S$. carpocapsae at a concentration of 500 infective juveniles per petri dish is shown in Fig. 2. At $18 \mathrm{~d}$ after infection, the proportion of dead I. scapularis females did not differ significantly between the 2 nematode species $\left(\chi^{2}=0.14\right.$, $\mathrm{df}=1, P=0.705)$. Similarly, cumulative mortality through time did not differ between nematode 


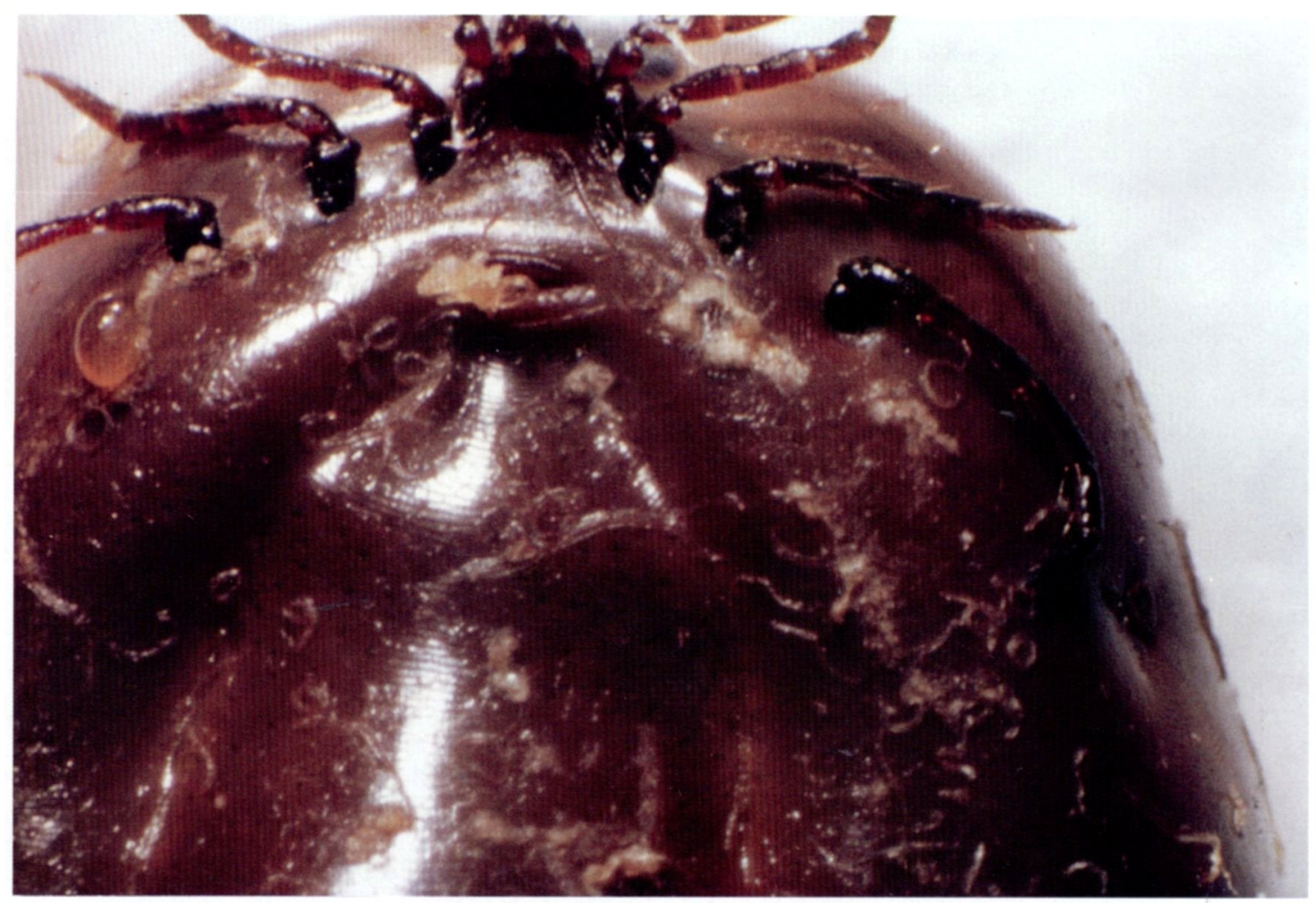

Fig. 1. Infective juvenile S. carpocapsae at the genital pore of an engorged female I. scapularis.

species (Kolmogorov-Smirnov 2-sample test, maximum difference $=0.16, P=0.93$ ).

Xenorhabdus nematophilus was recovered from cadavers of ticks infested by $S$. carpocapsae, and $X$. poinarii was recovered from ticks infested by $S$. glaseri. However, nematodes did not complete their life cycles inside ticks. Three weeks after death, no nematodes were found in tick cadavers. In contrast, when the cuticles of ticks were slit ar-

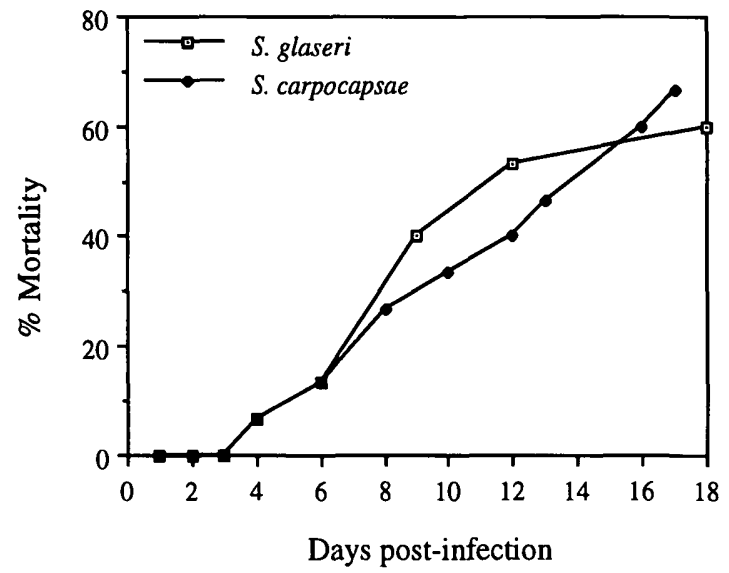

Fig. 2. Mortality of engorged adult female $I$. scapularis resulting from infection by $S$. carpocapsae and $S$. glazeri. tificially before infection, both nematode species completed their cycle, and infective juveniles were observed.

Mortality of engorged 1 . scapularis females is shown at different concentrations of infective juvenile $S$. carpocapsae in Fig. 3. The proportion of dead ticks after $17 \mathrm{~d}$ differed at different concentrations $(G=15.216$, $\mathrm{df}=4, P<0.005)$. However, trials with 50 through 3,000 infective juveniles per dish formed a nonsignificant subset $(G=2.543, \mathrm{df}$ $=3, P>0.3$ ). Thus, mortality of infected ticks

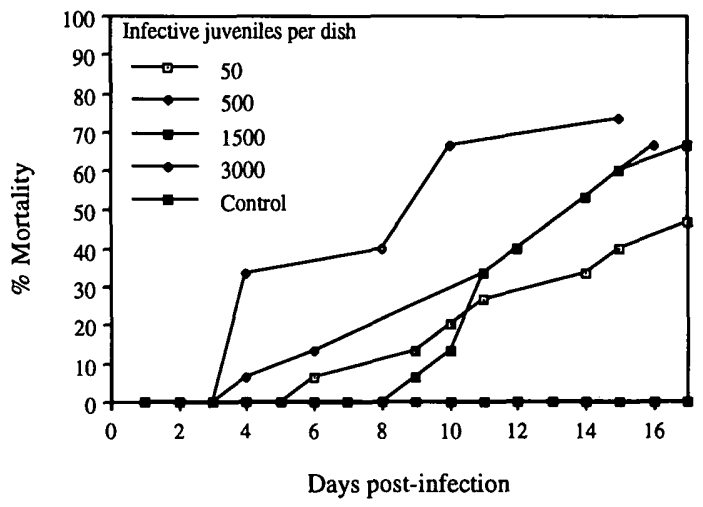

Fig. 3. Mortality of engorged adult female I. scapularis resulting from different concentrations of $S$. carpocapsae (at $23.5^{\circ} \mathrm{C}$ ). 


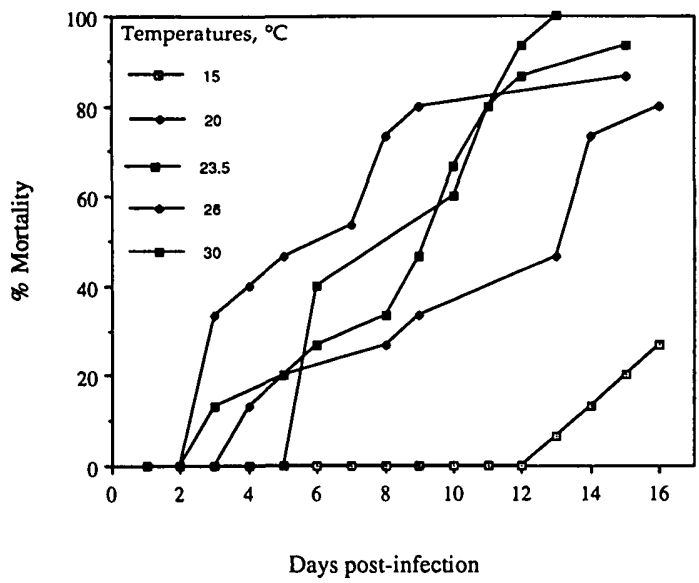

Fig. 4. Mortality of engorged adult female I. scapularis after exposure to $S$. carpocapsae at different temperatures $(3,000$ infective juveniles per petri dish).

differed significantly from the control, but mortality did not differ among concentrations. The $\mathrm{LC}_{50}$ was 347.8 infective juveniles per petri dish (containing 5 ticks).

Mortality of adult female I. scapularis challenged with 3,000 infective juveniles $S$. carpocapsae at different temperatures is shown in Fig. 4. Overall, the rate of tick mortality differed at different temperatures $(G=24.419, \mathrm{df}=3, P<<$ $0.005)$, but treatments at $20-30^{\circ} \mathrm{C}$ comprised a nonsignificant subset $(G=1.954, \mathrm{df}=2, P>0.3)$. Thus, mortality differed significantly only at the lowest temperature.

The mean weights of uninfected control ticks (mean $325.3 \mathrm{mg}, n=15$ ) did not differ significantly from that of infected ticks that survived (mean $293 \mathrm{mg}, n=21)(F=2.04 ; \mathrm{df}=1,34 ; P$ $=0.16)$. Ten infected females died after laying a few eggs, none of which hatched.

Fecundity of females that survived nematode infestation was measured by weighing the hatched egg mass (Fig. 5). Overall, there were no significant differences among treatments $(F=1.555$; $\mathrm{df}$ $=4,31 ; P=0.211$ ), but the ANOVA had low power $(\approx 0.4)$. The weights were normally distributed (Lillefors probability $=0.315$ ) as were the standard residuals (Lillefors probability $=0.511$ ), and variances were homogeneous $\left(F_{\max }=5.269 ; \mathrm{df}=3\right.$, $3 ; P>0.05)$. When we combined the infection treatments to increase the power of the test (Cohen 1988), and compared infected ticks, as a group, with uninfected controls (power $\approx 0.61$ ), the difference was significant $(F=5.461 ; \mathrm{df}=4,34$; $P=0.0255)$. Therefore, treatment with $S$. carpocapsae lowered fecundity, but there were no clear differences among different concentrations of nematodes.

\section{Discussion}

Neither S. carpocapsae nor S. glaseri were pathogenic to immature $I$. scapularis. In contrast,

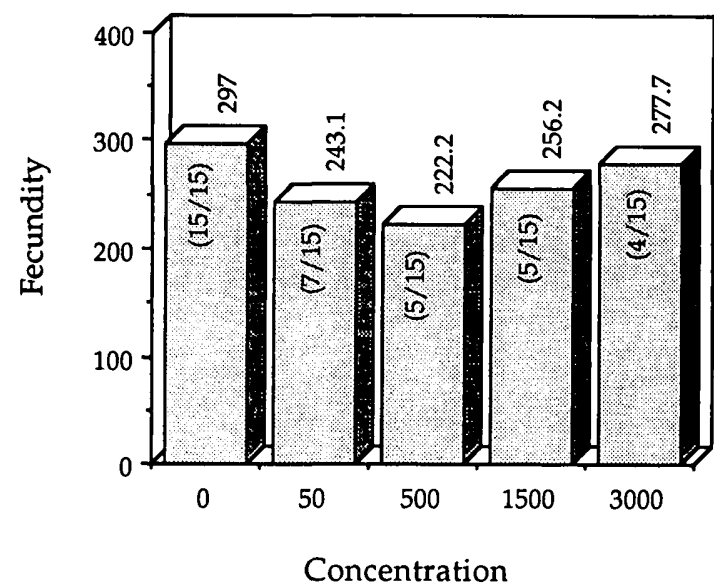

Fig. 5. Fecundity of surviving I. scapularis (Mean weight per tick with hatched eggs: $\mathrm{mg}$ ) after exposure to various concentrations of $S$. carpocapsae (0-3000 infective juveniles per dish).

these nematodes were pathogenic to engorged adult female ticks. No difference in pathogenicity was detected between S. carpocapsae and S. glaseri against engorged females. Symptoms observed in infected ticks are similar to those noted by other investigators (Samish and Glaser 1991).

Our results suggest that the genital pore is a route of entry for these entomopathogenic nematodes. We cannot exclude other routes of entry because our observations were only intermittent. However, the inability of nematodes to infect immature ticks is compatible with entry through the genital pore; the absence of the genital pore may protect immatures from nematode attack. The lack of pathogenicity to unengorged females may be explained by the fact that after engorgement, the genital pore is everted (Diehl et al. 1982), possibly allowing the penetration of nematodes.

Penetration of nematodes into other ticks remains controversial. Samish and Glazer (1991) reported that nematodes entered $B$. annulatus between the mouthparts. However, for the same tick species, B. annulatus, Genés organ was suggested as the entry point by Mauléon et al. (1993). In insects, steinernematid infective juveniles use oral and anal openings as routes of entry (Poinar 1979), with spiracles as an alternative route (Triggiani and Poinar 1976, Georgis and Hague 1981, Nguyen and Smart 1990). Finally, using their dorsal labial tooth, heterorhabditid nematodes may penetrate the insect hemocoel through soft intersegmental areas of the cuticule (Bedding and Molyneux 1982). Therefore, more studies are needed to clarify the route of nematode entry into ticks.

Boophilus annulatus is highly susceptible to steinernematids and heterorhabditids, whereas $B$. microplus and $A$. variegatum are highly resistant to these nematodes (Mauléon et al. 1993). H. bactoriophora is more pathogenic to engorged $B$. annulatus females than S. carpocapsae (strain DT) 
(Samish and Glazer 1992, Mauléon et al. 1993), and S. carpocapsae (strain All) is more pathogenic than S. glaseri (Mauléon et al. 1993). S. carpocapsae (strain DT) is more infective to engorged $B$. annulatus females than S. carpocapsae (strain All) (Samish and Glazer 1992). Clearly, susceptibility of ticks to entomopathogenic nematodes differs for different species and stages of ticks and nematodes.

The fact that Xenorhabdus spp. were recovered from ticks infected by $S$. carpocapsae and S. glaseri suggests that the infection caused tick death, even though the nematodes did not complete their life cycles inside the tick. Similar observations were reported for nematode infection of $B$. annulatus (Samish and Glazer 1991, 1992; Glazer and Samish 1993; Mauléon et al. 1993). Despite the high susceptibility of $I$. scapularis females to $S$. carpocapsae and S. glaseri, deer ticks are not suitable hosts for reproduction of these nematodes. We report here for the lst time that when the tick body is injured by slitting the cuticle, S. carpocapsae and $S$. glaseri successfully complete their life cycle and produce infective juveniles. Completion of the life cycle in noninsect hosts is rare for these nematodes, even when the host has been killed (Poinar 1989).

The rate of mortality seemed to vary proportionally with nematode concentration (Fig. 4), but the differences were not statistically significant. With 500 infective juveniles per petri dish containing 5 ticks, $\approx 65 \%$ were dead at $17 \mathrm{~d}$ after infection. Compared with other noninsect hosts (for example, spiders), which are killed only by relatively high numbers of infective juveniles (Poinar 1986), steinernematids are highly pathogenic to $I$. scapularis.

In earlier studies, mortality of B. annulatus females reached $100 \%$ within $8 \mathrm{~d}$ (Samish and Glazer 1992, Mauléon et al. 1993), whereas in our study mortality of $I$. scapularis did not reach $100 \%$ even at $17 \mathrm{~d}$ after infection. This difference may not actually reflect differences in susceptibility to nematode attack because the studies were performed at different temperatures. In the earlier studies, mortality of $B$. annulatus was determined at $26^{\circ} \mathrm{C}$, whereas our studies were performed at $23.5^{\circ} \mathrm{C}$. The optimal temperature for nematode activity is $26^{\circ} \mathrm{C}$ (Samish and Glazer 1992), and pathogenicity for $I$. scapularis declines at lower temperatures (Fig. 5). The $\mathrm{LC}_{50}$ for S. carpocapsae (strain All) was 372 against $B$. annulatus females (Samish and Glazer 1992), which was quite similar to the value of 348 per petri dish for $I$. scapularis females in the current study.

Georgis (1990) showed that the optimal temperature for insecticidal activity of steinernematid and heterorhabditid nematodes falls between 18 and $28^{\circ} \mathrm{C}$. High mortality rates of $B$. annulatus females were observed at 22 through $26^{\circ} \mathrm{C}$ (Samish and Glazer 1992). In our study, acaricidal activity of S. carpocapsae to I. scapularis was lowered at $15^{\circ} \mathrm{C}$ compared with trials at $20-30^{\circ} \mathrm{C}$. Therefore, low temperatures apparently limit acaricidal activity of these entompathogenic nematode strains. During the major peak of adult activity of $I$. scapularis in the northeastern United States (autumn), the ambient temperature is often below $15^{\circ} \mathrm{C}$. Thus, acaricidal activity of these entompathogenic nematode strains would probably be seriously compromised by the low temperatures in the natural environment.

The temperature range of infectivity of a nematode species or strain depends on its native region. S. feltiae (Filipjev) (strain N60), which is native to low temperature regions, is very active between 2 and $20^{\circ} \mathrm{C}$. In contrast, Heterorhabditis sp. Dl, which is native to high temperature regions, is very active between 26 and $29^{\circ} \mathrm{C}$ (Kaya 1990). Therefore, it would be worthwhile to test the pathogenicity of nematode species or strains native to low temperature regions against $I$. scapularis.

We measured tick fecundity by the weight of hatched egg masses and not just by the number of eggs. Our studies showed a significant difference in the fecundity of $I$. scapularis females between surviving ticks and uninfected control ticks. In contrast, Samish and Glazer (1992) found no effect of nematode infection on egg laying of surviving ticks. In view of the small sample size in our experiment, we cannot be certain that nematode infection affected the fecundity of surviving ticks. This subject deserves further study.

We conclude that under laboratory conditions, S. carpocapsae and S. glazeri are pathogenic to engorged I. scapularis females. However, it is not clear whether these nematodes would be effective against $I$. scapularis females under field conditions.

\section{Acknowledgments}

We thank S. R. Alm, I. Glazer, G. O. Poinar, Jr., and $T$. Yeh for constructive comments on early drafts of the manuscript. We are grateful to P. W. Johnson for his technical assistance. This work benefited from support by the Swiss National Foundation of Science, the Department of Plant Sciences at the University of Rhode Island, and the U.S. National Biological Service. This is contribution 3098 of the College of Resource Development, University of Rhode Island.

\section{References Cited}

Akhurst, R. J. 1980. Morphological and functional dimorphism in Xenorhabdus spp., bacteria symbiotically associated with the insect pathogenic nematodes $\mathrm{NeO}-$ aplectana and Heterorhabditis. J. Gen. Microbiol. 121: 303-309.

1982. Antibiotic activity of Xenorhabdus spp., bacteria symbiotically associated with the insect pathogenic nematodes of the families Heterorhabditidae and Steinernematidae. J. Gen. Microbiol. 128: 3061-3065.

Akhurst, R. J., and N. E. Boemare. 1990. Biology and taxonomy of Xenorhabdus, pp. 75-90. In R. Gaugler and H. K. Kaya [eds.], Entomopathogenic 
nematodes in biological control. CRC, Boca Raton, FL.

Barré, N., H. Mauléon, G. I. Garris, and A. Kermarrec. 1991. Predators of ticks Amblyomma variega tum (Acari: Ixodidae) in Guadaloupe, French West Indies. Exp. Appl. Acarol. 12: 163-170.

Bedding, R. A., and A. S. Molyneux. 1982. Penetration of insect cuticule by infective juveniles od Heterorhabditis spp. (Heterorhaditidae: Nematoda). Nematologica 28: 354-359.

Cohen, J. 1988. Statistical power analysis for the behavioral sciences. Erlbaum, Hillsdale, NJ.

Daniels, T. J., D. Fish, and R. C. Falco. 1989. Seasonal activity and survival of adult Ixodes dammini (Acari: Ixodidae) in southem New York State. J. Med. Entomol. 26: 610-614.

Diehl, P. A., A. Aeschlimann, and F. D. Obenchain. 1982. Tick reproduction: oogenesis and oviposition, pp. 277-350. In F. D. Obenchain and R. Glaun [eds.], Physiology of ticks. Pergamon, Oxford.

Duffy, D. C. 1991. Ants, ticks and nesting seabirds, dynamic interaction? pp. 242-257. In J. E. Loye and M. Zuk [eds.], Bird-parasite interaction: ecology, evolution and behaviour. Oxford University Press, Oxford.

Dunphy, G. B., and G. S. Thurston. 1990. Insect immunity, pp. 301-323. In R. Gaugler and H. K. Kaya [eds.], Entomopathogenic nematodes in biological control. CRC, Boca Raton, FL.

Gaugler, R. 1988. Ecological consideration in the biological control of soil inhabiting insects with entomopathogenic nematodes. Agric. Ecosyst. Environ. 24: 351 .

Gaugler, R., L. LeBeck, B. Nakagaki, and G. M. Bouch. 1980. Orientation of the entomogenous nematode Neoaplectana carpocapsae to carbon dioxide. Environ. Entomol. 9: 649-652.

Georgis, R. 1990. Formulation and application technology, pp. 173-191. In R. Gaugler and H. K. Kaya [eds.], Entomopathogenic nematodes in biological control. CRC, Boca Raton, FL.

Georgis, R., and N.G.M. Hague. 1981. A neoaplectanid nematode in the larch sawfly Cephalica lariciphila (Hymenoptera: Pamphiliidae). Ann. Appl. Biol. 99: 171-177.

Ginsberg, H. S. 1994. Lyme disease and conservation. Conserv. Biol. 8: 343-353.

Glazer, I., and M. Samish. 1993. Suitability of Boophilus annulatus replete female ticks as hosts of the nematode Steinernema carpocapsae. J. Invertebr. Pathol. 61: 220-222.

Kaya, Н. K. 1985. Entomogenous nematodes for insect control in IPM systems, pp. 283-302. In M. A. Hass and D. C. Herzog [eds.], Biological control in agricultral IPM systems, Academic, New York.

1990. Soil ecology, pp. 93-115. In R. Gaugler and H. K. Kaya [eds.], Entomopathogenic nematodes in biological control. CRC, Boca Raton, FL.

Klein, M. G. 1990. Efficacy against soil-inhabiting insect pests, pp. 195-214. In R. Gaugler and H. K. Kaya [eds.], Entomopathogenic nematodes in biological control. CRC, Boca Raton, FL.

Mather, T. N., J. Piesman, and A. Spielman. 1987. Absence of spirochetes (Borrelia burgdorferi) and piroplasms (Babesia microti) in deer ticks (Ixodes dam- mini) parasitized by chalcid wasps (Hunterellus hookeri ). Med. Vet. Entomol. 1: 3-8.

Mauléon, H., N. Barré, and S. Panoma. 1993. Pathogenicity of 17 isolates of entomophagous nematodes (Steinernematidae and Heterorhabditidae) for the ticks Amblyomma variegatum (Fabricius), Boophilus microplus (Canestrini) and Boophilus annulatus (Say). Exp. Appl. Acarol. 17: 831-838.

Nguyen, K. B., and G. C. Smart, Jr. 1990. Mode of entry and sites of development of Steinernema scapterisci in mole crickets. J. Nematol. 23: 267-268.

Oliver, J. H., Jr., M. R. Owsley, H. J. Hutcheson, A. M. James, C. Chen, W. S. Irby, E. M. Doston, and D. K. McLain. 1993. Conspecificity of the ticks Ixodes scapularis and Ixodes dammini (Acari: Ixodidae). J. Med. Entomol. 30: 54-63.

Piesman, J., and J. Gray. 1994. Lyme disease/Lyme Borreliosis, pp. 327-350. In D. E. Sonenshine and T. N. Mather [eds.], Ecological dynamics of tick-borne zoonoses, Oxford University Press, London.

Poinar, G. O., Jr. 1979. Nematodes for biological control of insects. CRC, Boca Raton, FL

1986. Entomogenous nematodes, pp. 95-121. In B. D. Franz [ed.], Biological plant and health protection. G. Fisher, Stuttgart.

1989. Non-insects hosts for the entomogenous rhabditoid nematodes Neoaplectana (Steinemematidae) and Heterorhabditidis (Heterorhabditidae). Rev. Nematol. 12: 423-428.

Samish, M., and I. Glazer. 1991. Killing ticks with parasitic nematodes of insects. J. Invertebr. Pathol. 58: 281-282.

1992. Infectivity of entomopathogenic nematodes (Steinernematidae and Heterorhabditidae) to female ticks of Boophilus annulatus (Arachnida: Ixodidae). J. Med. Entomol. 29: 614-618.

Silverman J., E. G. Platzer, and M. K. Rust. 1982. Infection of the cat flea, Ctenocephalides felis (Bouche) by Neoaplectana carpocapsae (Weiser). J. Nematol. 14: 394-397.

Sokal, R. R., and F. J. Rohlf. 1981. Biometry, 2nd ed. Freeman, San Francisco.

Solomon K. R. 1983. Acaricide resistance in ticks, pp. 273-296. In C. E. Cornelius and S. F. Simpson [eds.] Advances in veterinary science and comparative medecine, vol. 27. Academic, New York.

SYSTAT. 1992. SYSTAT for Macintosh, version 5.2 . SYSTAT, Evanston, IL.

Triggiani, O., and G. O. Poinar, Jr. 1976. Infection of adult Lepidoptera by Neoaplectana carpocapsae (Nematoda). J. Invertebr. Pathol. 27: 413-414.

Wilson, M. L., and R. D. Deblinger. 1993. Vector management to reduce the risk of Lyme disease, pp. 126-156. In H. S. Ginsberg [ed.], Ecology and environmental management of Lyme disease. Rutgers University Press, New Brunswick, NJ.

Woodring J. L., and H. K. Kaya. 1988. Steinernematid and Heterorhabditid nematodes: a handbook of techniques. Southern Cooperative Series Bulletin 331. Arkansas Agricultural Experiment Station, Fayetteville, AR.

Woolf, M. C. 1968. Principles of biometry. Van Nostrand, Canada, Toronto.

Received for publication 22 February 1995; accepted 23 June 1995. 